\title{
Ferrovia e Turismo Cultural - Alternativa para o Futuro da Vila de Paranapiacaba (SP)
}

\author{
Thiago Allis ${ }^{1}$
}

RESUMO: A meta do trabalho é demonstrar que a associação entre a preservação do patrimônio - através de sua interpretação -, e o turismo ferroviário é um instrumento eficaz na formatação do destino voltado ao turismo cultural de base sustentável. Para tanto, foi estudado o contexto históricoda ferroviapaulista, apontandoalguns referenciais que fizeram o modal rodoviário ser priorizado em detrimento do ferroviário. Após um longo período de abandono, a Vila de Paranapiacaba, local de expressão da cultura ferroviária iniciada na segunda metade do século XIX, é cogitada como um forte atrativo para o lazer cultural, atividade que pode ter seu efeito otimizado se associada com a ferrovia.

PALAVRAS-CHAVE: interpretação patrimonial, turismo sustentável, turismo cultural, turismo ferroviário, ferrovias turísticas, patrimônio histórico, Paranapiacaba/SP.

ABSTRACT: The main objective of this work is to show that the association between heritage preservation, through its interpretation, and railway tourism is a good method devoted to cultural tourism, with a sustainable base. For this reason, the history of Paulista railway was studied, showing some references that made highways to have priority in detriment to railways. After a long period on abandon, the Vila of Paranapiacaba, São Paulo, a place that express the start or beginning of the railway culture at the second half of XIX century, is mentioned as an interesting point of cultural tourism, an activity that can be maximized if associated to a tourist railway.

KEYWORDS: heritage interpretation, sustainabletourism, cultural tourism, railway tourism, tourist railways, historic heritage, Paranapiacaba/SP.

1. Aluno do curso de bacharelado em Turismo da Escola de Comunicações e Artes da Universidade de São Paulo Bolsista de Iniciação Científica da FAPESP - Fundação de Amparo à Pesquisa no Estado de São Paulo. (2002).

E-mail: lugarondepeixepara@hotmail.com 


\section{Introduçāo}

Criticamente degradada, a Vila de Paranapiacaba - distrito de Santo André, na grande São Paulo - vem sendo, há mais de duas décadas, objeto de discussões e projetos que ensejam a revalorização de seu patrimônio histórico.

Invariavelmente, esses trabalhos delegam ao turismo uma função premente no processo de reordenamento da Vila, em função da singularidade dos recursos naturais e culturais. Como exemplo, pode-se citar o Plano de Desenvolvimento Sustentável da Vila de Paranapiacaba, de 1999, e o Plano Patrimônio, de 2002.

Por isso, intentou-se, sob os auspícios dos estudos de Turismo, entender o cenário atual de Paranapiacaba e fazer algumas recomendações que estimulem o turismo em sua forma sustentável na Vila. Sua cultura material, em torno da estrada de ferro Santos-Jundiaí, é caracterizada pelas construções em estilo inglês na Parte Baixa da Vila, que datam de meados do século XIX (Monteiro, 1995). Sendo a essência da gênese da Vila a estrada de ferro Santos-Jundiaí, a temática ferroviária atrelada ao turismo cultural pode ser um importante vetor da valorização histórica da Vila e sua formatação como destino turístico.

O embasamento teórico para este estudo sustenta-se no projeto de interpretação do patrimônio (Goodey, 2002; Goodey; Murta, 2002) e no conceito de preservação ativa (Pellegrini Filho, 2001). Pretende-se, portanto, propor uma argumentação em favor da valorização turística do patrimônio cultural da Vila de Paranapiacaba, revestido de uma função dinâmica com vistas ao lazer.

A pesquisa, apoiada pela Fundação de Amparo à Pesquisa do Estado de São Paulo (FAPESP), foi feita através de levantamentos bibliográficos, entrevistas, pesquisas de campo e aplicação de 101 questionários de demanda entre os dias 27 e 28 de julho de 2002 .

O trabalho está dividido em quatro partes. Na primeira parte, elabora-se um breve histórico da ferrovia no Estado de São Paulo, assim como o papel de destaque que Paranapiacaba exerceu no processo de expansão deste modal de transporte, bem como fornece subsídios para a discussão em torno do turismo cultural e da utilização do trem para tal. Na segunda, criou-se um panorama atualizado sobre a Vila, apresentando alguns aspectos de sua história e de sua atual situação. Na terceira parte, são feitas algumas propostas pela integração dos temas discutidos e na quarta, as conclusões possíveis ao momento.

\section{Ferrovia, Cultura e Turismo}

\section{Ferrovia no Brasil e em São Paulo}

No início da Primeira República, o café era a mola propulsora da economia nacional. As maiores áreas de produção estavam no Vale do Paraíba e no chamado Oeste Paulista, que abrangia as regiões deCampinas, Limeira, Piracicaba, Araraquara e Ribeirão Preto.
O elemento-chave que permitia a manutenção da produção em frente a essa expansão geográfica era o intricado sistema de ferrovias que se desenvolvera a partir da "célula-mãe", a estrada de ferro Santos-Jundiaí - ou The San Paulo (Brazilian) Railway Co. No entanto, a partir da década de 1930, após o crash da Bolsa de Nova York, as ferrovias vão passando por uma constante queda de importância nas prioridades nacionais no âmbito dos transportes. A partir de então, a produção, que alimentava - e justificava - a contínua expansão do sistema ferroviário paulista, viu cair drasticamente seus números.

O problema crescente da desvalorização do café em face do mercado mundial culminou com a disseminação dorodoviarismo no Brasil, no governo de Washington Luíz, cuja administração se norteou pelo lema "governar é construir estradas", esse processo é acentuado na década de 1950, quando o presidente Juscelino Kubitschek adota uma política de continuísmo da tendência rodoviarista. Após 1950, abre-se a economia brasileira ao capital externo, tendo na indústria automobilística um dos principais símbolos de seu governo (Rocha, 1986).

No setor ferroviário, em 1957, é criada a Rede Ferroviária Federal S/A (RFFSA), que englobou todas as companhias ferroviárias estatizadas ao longo da década de 1950. Desde então, o que se viu foi um lento abandono do transporte ferroviário, processo que resulta, na década de 1990, no total sucateamento e atraso das ferrovias brasileiras, com pouca importância no transporte de cargas e insignificância no trânsito de passageiros.

Com a nova política do governo, a partir de 1997 as estatais ferroviárias começam a ser privatizadas. Com efeito, apesar de se notar certa melhora em alguns pontos,

cinco anos depois de iniciado o processo de privatização das antigas ferrovias estatais, a maioria das empresas nāo conseguiu cumprir metas contratuais de transporte de carga a rede se concentra na mão de apenas três grandes grupos e cerca de $25 \%$ da malha ferroviária está inoperante (Santos, 2002).

\section{Turismo, Transportes e o Trem}

A atividade turística só passa a ser organizada, com um sistema de produção e consumo de destinos turísticos de forma globalmente ampla e mais democratizada, depois da Segunda Grande Guerra (Harvey apud Barreto, 1999). No Brasil, a preocupação com o ordenamento do setor passa a figurar em fins da década de 1960 e início de 1970, através da atuação do atual Instituto Brasileiro de Turismo Embratur (Cruz, 2000).

O quesito transporte é, para o planejamento turístico, um dos elementoschave para que a atividade turística se concretize. Ele é o meio, a ferramenta que viabiliza o ciclo da produção de turismo, ou seja, faz com que produto e consumidor sejam postos em contato, ligando as áreas de destino às de origem dos turistas, 
facilitando o movimento de pessoas (Page, 2001).

No entanto, ademais das características estruturais e logísticas, o transporte também mostra sua importância quando da composição do produto turístico. Por isso, Page (2001) atesta que "o transporte também poderá constituir o ponto focal da atividade turística”, e não simplesmente um elemento de natureza prática.

Em relação ao transporte ferroviário, atualmente, o país conta apenas com três linhas regulares, que estão sob concessão da iniciativa privada e foram responsáveis, em 2000, pelo transporte de 1.308 .103 passageiros. Destaca-se que somente nas linhas rodoviárias interestaduais e internacionais, foram transportados mais de 132 milhões de passageiros (Ministério dos Transportes, 2002).

Porém, mesmo num panorama em que o transporte ferroviário de passageiros é ínfimo se comparado com o de outros modais, esboça-se uma certa atividade turística vinculada a determinados trechos de ferrovias. Em relação ao transporte turístico de passageiros, estima-se que cerca de $496 \mathrm{mil}$ ou 1,3\% dos turistas domésticos tenham utilizado as ferrovias (Palhares, 2002).

A Revista Ferrovia (1985) mostra a potencialidade do trem para o turismo:

(...) o desejo de "andar de trem" adquire um aspecto fantasioso, no Brasil, devido às raras oportunidades que se ensejam para que possamos viajar sobre linhas de ferro. (Está faltando turismo..., 1985:26-7).

Algumas dessas ferrovias vêm atraindo a atenção de movimentos preservacionistas, o que faz a oferta de passeios turísticos aumentar gradativamente no país. É o caso da Associação Brasileira de Preservação Ferroviária - ABPF, fundada em 1977 por Patrick Dollinger (Barbosa, 2001; Associação Brasileira de Preservação..., 2002). Uma das formas bem-sucedidas de preservação do patrimônio ferroviário é através de sua ressignificação, ou seja, o material rodante que está se deteriorando em pátios ferroviários ganha nova função quando de sua restauração, a turística. Nesse sentido, em 1981, começou a funcionar a primeira ferrovia turística do Brasil, ertre Campinas e Jaguariúna.

Sugere-se, enião, que a reduzida malha ferroviária exerça certa atração à exploração turística, pois, uma vez que a ferrovia está no imaginário das pessoas mais idosas vinculada a momentos importantes da imigração, por exemplo, os caminhos de ferro passam a ser atrativos até pela sua quase inexistência. A curiosidade e o tom de nostalgia são, portanto, os mais importantes fatores de atração às chamadas ferrovias turísticas, que compõem uma parcela dos produtos e destinos turísticos de algumas regiões do Brasil, como é o caso da ferrovia Curitiba a Paranaguá, no Paraná, e do Trem do Vinho, no Rio Grande do Sul. A Tabela “'Linhas Ferroviárias turísticas no Brasil' " (ver Anexo) ${ }^{2}$ traz alguns exemplos de outras linhas ferroviárias

2. Esta tabela foi elaborada conforme as informaçōes eram confirmadas. Segundo Barbosa (2001), há 24 trecho ferroviários turísticos no Brasil. Este número merece ser revisto por uma pesquisa mais apurada, que tenha os tren turísticos brasileiros como objeto de interesse. turísticas, que, associadas às atrações locais, vêm fortalecendo a visibilidade do destino e criando uma marca de identidade entre o passeio de trem e a localidade em questão, como a estrada de ferro São João Del Rey-Tiradentes.

\section{Turismo Cultural: vislumbre de possibilidades}

\section{Interpretação do Patrimônio}

O conceito, ainda pouco explorado e aplicado no Brasil, tem origem nos trabalhos de Freeman Tilden. De início, como diretorde um parque norte-americano, o "pai da interpretação" tentou buscar uma forma de conscientizar os visitantes em relação à preservação e ainda terem uma visita dinâmica e empolgante (Goodey; Murta, 2002).

Com o tempo, o conceito se dinamizou e, nos anos 80, ganhou o campo do turismo, sendo ampliado seu uso ao patrimônio cultural. Essa necessidade parte, porém, do marco conceitual para a interpretação do patrimônio, que o define como a atividade educacional que aguce a curiosidade do visitante, saindo do lugar-comum de visitas iticas tradicionais. O turista, quando volta do destino escolhido, deve sentir-se mais rico de conhecimento (Tilden apud Murta; Albano, 2002).

Além disso, deve-se destacar a capacidade de surpreender através das peculiaridades locais. Conveniente, é a opinião de Murta; Albano (2002):

A tradiçāo da interpretação do patrimônio natural e cultural sinaliza justamente o valo único de um determinado ambiente, buscando estabelecer uma comunicação com o visitante, ampliando seu conhecimento. Em outras palavras, visa estimular suas várias ormas de olhar e aprender o que lhe é estranho.

Segundo Tilden (apud Murta; Albano, 2002), "não basta apenas instruir, mas provocar". Esta constatação leva a um caráter essencialmente educativo para o turismo - independentemente de faixa etária -, uma vez que deve haver uma contrapartida do interlocutor quando da atividade turística. ${ }^{3}$

Um outro conceito relevante para a discussão da interpretação do patrimônio é a interação não somente do visitante com o conjunto de recursos disponíveis de uma

3. Recobrando essa idéia em Jean Piaget, percebem-se algumas consideraçōes que foram motivo de revolução na educação. Tr risma geral, a teoria piagetiana, de cunho construtivista, sugere que, para uma educação eficiente indelével,é necessário que se promova o desenvolvimento da inteligência através de induçōes provocativas, desafios. "desequilibraçōes" criadas artificialmente pelo educador (Lima, 1984). Considerando, então, o turismo cultural pela interpretaçăo do patrimônio, pressupōe-seo caráter educativo daquela atividade. Dessa forma, quando Tilden propōe a provocação como forma de interpretar o patrimônio, a educaçăo pelo turismo entra em consonância com a teoria de Piaget, reafirmando seu peso na atividade na educaçăo. 
localidade, mas também da população local. Afinal, os atores que mais conhecem a realidade local são certamente os autéctones, que têm a vivência mais enraizada e profunda sobre o lugar (Goodey, 2002).

De forma geral, pode-se perceber que a interpretação do patrimônio encontra sua função em algo que no Brasil é bastante problemático: a educação, tanto para o visitante quanto para aquele que recebe o turismo em sua localidade. Por isso, a atividade turística pode ser uma forma de atuação, responsável e socialmente engajada, ‘uracterística que compõe a almejada sustentabilidade.

Esse é um novo paradigma que deve ser incluído nos trabalhos, pesquisas e atuações no campo do turismo, uma vez que a tradição brasileira insiste em preparar e valorizar somente o lado da demanda, ou seja, o turista, deixando para segundo plano os anseios e as necessidades dos "anfitriōes". Em relação a Paranapiacaba, este é um tema preocupante, pois, visto que grande parte dos habitantes de Parabapiacaba pouca intimidade tem com a simbologia do lugar, a participação e inclusão dos moradores no novo planejamento turístico esbarra em problemas de identidade. $\mathrm{O}$ tema será tratado mais adiante.

\section{Preservação Ativa}

Na esteira da interpretação, o conceito de preservação ativa complementa a argumentação em favor do turismo cultural. Em muitos núcleos urbanos, como é o caso de Paranapiacaba, apesar de seu reduzido tamanho, o que antes tinha uma função industrial, por exemplo, pode hoje ser obsoleto. Ao longo da História, este processo deixa marcas no espaço - o patrimônio cultural -, uma vez que a cidade é um palco de relações sociais e sua paisagem está impregnada da dimensão de vários tempos (F:ai i 2001). Assim, o conceito de patrimônio é um desdobramento secundário desta característica, motivo pelo qual Pellegrini Filho (2001) conceitua patrimônio cultural ${ }^{4}$ como

(...) todo e qualquer artefato humano que, tendo um forte componente simbólico, seja de algum modo representativo da coletividade, da regiāo, da época específica, permitindo melhor compreender-se o processo histórico. (...) O caráter representativo de uma cultura ainda que seja, na realidade, apenas representativo de um pormenor dessa cultura, the dá a condiçāo de bem patrimonial.

Num contexto em que símbolos culturais da cidade - por exemplo, edifícios históricos - não têm mais a mesma utilidade quando de sua construção, nota-se uma

4. Considera-se neste trabalho putrimôninio culturulu um sinônimo de putrimônnio histórico. No entanto, dado o efeito mai abrangente do termo culturur, sugere-se como mais viável o uso de patırimônio cultural. degradação bastante acentuada. Caso típico desse processo são as zonas portuárias e "centros velhos" das cidades mais antigas.

Assim, reconhecendo-se a representatividade que esses símbolos resguardam, a preservação ativa pode atuar de forma a ressignificá-los, dando-lhes outros fins convenientes e integrando-os às sociedades a elcs contemporâneas. Trata-se de uma reciclagem de usos, gerando também novos hábitos c uma "função útil à sociedade", corroborando o anseio pelo progresso com o cuidado para que sua simbologia não se perca (Pellegrini Filho, 2001).

Caso típico de preservação ativa é o Bairro do Recife, em Recife (PE). Depois de um longo processo de decadência, o local passou a contar, desde 1987, com políticas de revitalização. (Recife. Prefeitura Municipal, s.d.). Também, cita-se a Estação das Docas em Belém (PA), que, de galpões portuários abandonados, se transformou num centro gastronômico e opção de lazer às margens da Baía de Guajará.

Pa Maranapiacaba, o Plano Patrimônio (2002), apesar de seus pontos questionáveis, tendo o turismo como um dos eixos principais, suscita uma forma específica dessa atividade para a Vila, o turismo cultural. Esta prática é essencialmente urbana e, segundo experiências mundiais, é praticada por turistas com média etária maior e com maior poder aquisitivo, o que dá indícios de maiores ganhos com gastos turísticos. Em contrapartida, esse é um público mais exigente, que requer serviços mais especializados e de melhor qualidade, ainda que tenha de pagar mais por isso.

Sugere-se, então, associar o turismo praticado no núcleo urbano de Paranapiacaba, com a valorização do patrimônio cultural, a outras alternativas de utilização do patrimônio turístico da Vila, que venham a ser propostas num futuro Plano de Desenvolvimento Turístico de Paranapiacaba.

Ademais, há cerca de dois anos, a World Monument Fund (WMF), já reconhece a representatividade do patrimônio cultural da Vila - motivo pelo qual considera perigosa a sua perda e a inclui na "Lista dos Bens com Perigo de Degradação". A WMFé uma instituição norte-americana, financiada pela American Express, com fins preservacionistas. Bienalmente, emite uma lista com os 100 sítios históricos ou arquitetônicos ameaçados de destruição ou degradação. Paranapiacaba foi incluída pela segunda vez nesta lista e, em abril de 2002, recebeu verba de US\$ 50.000 para arestauração da casa 33 da Rua Rodrigues Quaresma, na Parte Alta, onde deverá ser construído um centro de documentação da Vila (Angiolilo, 2002). Bonnie Burnham (apud Angiolilo, 2002), presidente da instituição, sugere mudanças em Paranapiacaba da seguinte maneira:

(...) é preciso trabalhar três elementos em Paranapiacaba: restaurar a ligação ferroviária com S. Pauto (...); recuperar, com auxílio da iniciativa privada, trens e o maquinário ferroviário antigos, além dos edifícios públicos; e, por fim, investimento privado nas casas. 


\section{Caracterizaçāo Geral da Vila de Paranapiacaba}

Localização, Aspectos Históricos e a Estrada de Ferro Santos-Jundiaí

Localizada no topo da Serra do Mar, a Vila de Paranapiacaba é o último ponto entre o Planalto Paulista e a Baixada Santista, distante aproximadamente $50 \mathrm{~km}$ do centro de São Paulo. Pertencente ao município de Santo André desde janeiro de 2002, o sítio é cercado pela Mata Atlântica, ainda bastante preservada nesse local.

A paisagem urbana é marcada pela tipologia inglesa das construções, remanescente da colonização proveniente da instalação da estrada de ferro SantosJundiaí. A ferrovia foi idealizada por Irineu Evangelista de Souza, o Barão de Mauá, e entrou em funcionamento em $1867 \mathrm{com}$ tecnologia e materiais ingleses - motivo pelo qual foi apelidada de Inglesa.

Paranapiacaba, que se chamou Alto da Serra até 1946, é classificada como uma típica model company town, em função de sua criação e funcionamento serem exclusivamente voltados às atividades da ferrovia - no caso, uma single enterprise (Minami apud Monteiro, 1995). O pequeno núcleo urbano, com cerca de 4,3 km², divide-se em duas partes (Monteiro, 1995):

- Parte Baixa: surgiu entre 1860 e 1900; subdividida em duas regiões:

- Vila Veílıa ou Varanda Velha: foi a primeira parte da Vila a ser construída. Nela, moravam os trabalhadores que vieram para o local para a construção da ferrovia, num amontoado de casas e oficinas ao longo da rua Direita;

- Vila Nova ou Vila Martin Smith: com a necessidade de mais funcionários para o funcionamento e manutenção da ferrovia, foi construída uma segunda área residencial. Contígua à Vila Velha, a Vila Martin Smith contava com certo planejamento e hierarquia nas construções. Mormente construídas com pinho-deriga importado, as casas tinham todos os serviços que até então eram raridade (calefação, água encanada, etc.).

- Parte Alta: ocupaçãomais recente caracteriza-se principalmente pela imigração de portugueses e espanhóis, onde a arquitetura é marcada pela alvenaria. Neste caso, a companhia já não tinha jurisdição, motivo pelo qual o modelo de desenvolvimento foi espontâneo e sem planejamento.

O pátio ferroviário, onde se localiza a estação e a torre do relógio -- datado de 1888 e em funcionamento -, é transposto através da Ponte Metálica, construída em 1899.

De grande necessidade nacional, a estrada de ferro Santos-Jundiaí inicia suas operações com um moderno sistema de funiculares, até então nunca usado em situação semelhante. Com $139 \mathrm{~km}$, a ferrovia vence um desnível de cerca de $800 \mathrm{~m}$, entre a raiz la serra e o planalto (Caldeira, 1997).

Sobre a ferrovia, Cyrino (2000) afiança:
A seção da Serra após sua conclusão tornou-se mundialmente famosa devido ao sistema de tração adotado, uma vez que usualmente o sistema funicularsomente era utilizado em pequenos trechos para o transporte de passageiros e nunca para o transporte de quatro toneladas de cargas e pessoas.

Apesar de impressionante, o processo de transporte era lento. Este detalhe técnico é um dos responsáveis pela atual forma da Vila, pois o movimento de trens fez mudar a feição da pequena Vila ferroviária no topo da Serra do Mar, conferindo ao lugar çıı efervescência. Sobre isso, afirma Monteiro (1995):

Ali os passageiros tinham de aguardar os vagōes descerem a serra. Por isso, se não fizessemparte do primeiro grupo, era costume os passageiros descerem dotrem para um café, uma olhada na Vila Inglesa, um passeio na estação, até chegar sua vez de descer a serra.

A estrada de Ferro São Paulo Railway foi a mais rentável da América do Sul e a mais importante no processo de desenvolvimento do Brasil. Por conta de sua construção, em 1867 foi implantada a Vila Ferroviária, apresentando um modelo de urbanização e soluções habitacionais até então raríssimas no país (Santo André. Prefeitura Municipal, 2002).

Com a decadência da ferrovia brasileira, após a década de 1960, a Vila perde sua função e cai no obsoletismo. Um dos fatores motivadores foi a desativação do sistema de funiculares, após a construção do segundo sistema de transporte em 1974, a cremalheira-aderência (Ferreira, 1998).

Desde então, ainda que se tenha tombado a Vila em 1987 em âmbito estadua pelo Condephaat, o patrimônio cultural assentado sobre a Vila de Paranapiacaba continua em risc de degradação. Somente por um período restrito, entre 1986 e 1989, a ABP: operou um passeio entre a Estação da Luz e o $5^{\circ}$ e o $4^{\circ}$ patamares, funcionando uma vez por semana (Prosperi; Grostein, 1999).

Estagnada economicamente e monótona socialmente, seus moradores migram para regiões do Grande ABC ou São Paulo. Aqueles que insistem em ficar utilizam a Vila como "dormitório", uma vez que possibilidade de emprego passa a ser escassa; quando não são desempregados. As considerações do Plano de Desenvolvimento Sustentável da Vila de Paranapiacaba apontam que, em 1999, somente $37,5 \%$ dos moradores da Parte Baixa trabalhavam na Vila, enquanto 46,6\% da Parte Alta e 57,4\% da Parte Baixa estavam sem emprego (Prosperi; Grostein,1999).

Sobre este cenário, Prosperi; Grostein (1999) ponderam:

Um fato é que a Vila sempre manteve uma população residente, mais ou menos arraigadas às raizes históricas da Vila, e em nenhum periodo reduzida a ponto de caracterizar-secomo desabitada, porémhoje em dianāoé uma Vilavoltadapara atender 
exclusivamente à ferrovia. A Vila mantém seu forte caráter de local de moradia, porém comportando uma populaçāo bastante diversa daquela que sempre foi associada à Vila. Os antigos ferroviários, que eram praticamente maioria na Vila, representam hoje uma parcela infima da populaçāo.

Apesar desse cenário pessimista, o valor tecnológico das instalações ferroviárias e a arquitetura da Vila, somados ao bucolismo da região de Mata Atlântica, suscitam discussões que põem o turismo como forma de revitalização da economia e da vida social de Paranapiacaba. Prova do reconhecimento de sua importância patrimonial, a Vila foi recentemente tombada em nível federal pelo IPHAN, o que, em teoria, significa que os recursos histórico-culturais ali presentes gozam de mais rigor no tocante à preservação.

Tema importante da discussão do turismo é a integração de uma população que talvez tenha pouca relação de afeto com a Vila - somente $26,5 \%$ da população nasceu no local -, mas que, como autóctone, é parte vital para o sucesso do planejamento turístico.

\section{O Acesso de Trem}

Na Estação da Luz, no centro de São Paulo, partem trens a cada 20 minutos para Rio Grande da Serra, de onde são oferecidos cinco horários diários de conexões aos sábados, domingos e feriados para a Vila ${ }^{5}$. Há ainda a possibilidade do ônibus, que parte durante toda a semana do Terminal de Santo André e da Estação de Trem de Rio Grande da Serra com destino a Paranapiacaba. A seguir, seguem algumas informações sobre o volume de tráfego à Vila.

\section{TABELA 1 - NÚMEROS DE EMBARQUE PARA O MESES DE AGOSTO DE}

\section{E JULHO DE 2002}

\begin{tabular}{lcc}
\hline Variáveis & Agosto de 2001 & Julho de 2002 \\
\hline Média de Sábado & 146 & 840 \\
Média de Domingo e Feriado & 162 & 1.285 \\
\hline
\end{tabular}

Fonıe: CPTM - Gerência das linhas AVD (julho de 2002)

5. Para mais informaçōes, contatar a Cia. Paulista de Trens Metropolitanos (CP'TM): 0800-550121.
Os dados trazem algumas elucidações acerca do acesso ferroviário à Vila. Primeiro nota-se que o movimento aos domingos éligeiramente maior; segundo, que o número total de embarques de 2002 é bastante maior que em 2001. Este fato mostra que, mesmo não havendo o serviço de trens durante a semana em julho de 2002, os embarque uram $245 \%$ maiores, o que pode levar à conclusão de que a visitação turística aumentou em 2002.

\section{Poder Público}

Oficialmente atuando na Vila de Paranapiacaba desde janeiro de 2002, a Prefeitura de Santo André, através da Subprefeitura de Paranapiacaba e do Parque Andreense, fechou um contrato com a Rede Ferroviária Federal S/A (RFFSA), no valor de $\mathrm{R} \$ 2.101 .700,00$ que deverão ser pagos em dezoito prestações - afora a entrada de $10 \%$ sobre esse valor que já foi pago. Foram adquiridos 4,26 milhões de $\mathrm{m}^{2}$ de terreno e outros 225,9 mil m² de área construída (Santo André. Prefeitura Municipal, 2002)

Dos trabalhos contratados pela Prefeitura, destacam-se:

\section{- O Plano de Desenvolvimento Sustentável da Vila de Paranapiacaba}

Realizado em 1999 pelo Laboratório de Urbanismo da Metrópole (LUME) da Faculdade de Arquitetura e Urbanismo da Universidade de São Paulo, teve como principais triefas avaliação geral da Vila à época e, no tocante ao turismo, uma abordagem calcada no ecoturismo. Dentre os principais pontos analisados, estão a criação de um panorama de conservação do patrimônio, uso e ocupação do solo; e a pesquisa socioeconômica e análise das atividades turísticas.

A pesquisa socioeconômica, feita através de 107 entrevistas a turistas em maio de 1999, traz o perfil bio-socioeconômico do visitante, assim como motivos de visita, pontos de interesse e outros aspectos relacionados à atividade turística em Paranapiacaba.

No item em que se propõem intervenções em Paranapiacaba, é privilegiado o ecoturismo como forma de visitação da Vila. Dentre as sugestões, estão medidas que facilitem a circulação de pedestres na Vila, deslocamento de estradas e reordenamento de caminhos internos, novo paisagismo que incluiu um parque público, a criação de um centro de referência da Mata Atlântica e um plano ecoturístico.

\section{- Plano Patrimônio}

Elaborado pela Marketing Systems, foi entregue em maio de 2002 e o cerne deste projeto está ligado à questão cultural e sua valorização turística. Sua proposta é dividida em três partes: 
- fase I: diagnóstico;

- fase II: formulação de estratégia de desenvolvimento;

- fase III: plano operacional.

Estão propostas algumas ações urgentes nas seguintes atividades no biênio 2001/2002, com gasto público estimado em cerca de R \$4,9 milhões com sinalização urbana e turística e do mobiliário urbano, reforma do sistema viário e paisagismo, captação de investimentos, um programa de segurança e outras medidas.

Algumas das atividades pressupostas no Plano já estão em andamento, como a criação e dotação de infra-estrutura de um Centro de Informação Turística, sinalização dos principais pontos de valor histórico, o início da restauração do Antigo Mrrado e o projeto Ateliers

\section{Atividade Turística no Núcleo Urbano de Paranapiacaba}

Além de visitas exploratórias aos finais de semana, foram aplicados 101 questionários aos visitantes, nos dias 27 e 28 de julho de 2002 . Visto que o interesse residia nos atrativos culturais, a pesquisa foi feita a partir de pontos estratégicos no núcleourbano,taiscomo o Castelinho, MuseuFunicular,Passarela Metálica, Centro de Informações Turísticas e ruas da Parte Baixa no geral, Estação Ferroviária e o trem.

A única atividade que aparentemente movimenta a fraca economia de Paranapiacaba é o turismo. Ainda que não se tenham dados sólidos sobre o assunto, nota-se um fluxo espontâneo de turistas aos fins de semana, que procuram as trilhas ecológicas do entorno ou pela calma e ambiente bucólico do núcleo histórico.

Vale notar que esse movimento não passa por qualquer tipo de organização ou planejamento tampouco mensuração, ficando por conta de pequenos comerciantes se organizar na recepção dos visitantes. Os serviços oferecidos são basicamente lanchonetes, barracas de bebidas, artesanato comercializado ao ar livre e dois museus, aiśn de um centro de informações turísticas provido pela Prefeitura Municipal de Santo André. Há ainda uma cooperativa de venda de artesanato e alimentos produzidos por moradores.

Segundo o Plano Patrimônio, o fator de utilização geral dos recursos potenciais da Vila em função de seu potencial integral é de somente $37 \%$. Em frente a este desempenho, fica nítida o quanto ainda a atividade turística tem por se desenvolver no local, principalmente se consideradas as especificidades internas e conjuntura de posicionamento.

Em relação ao patrimônio cultural, alguns pontos são referências para o turista que busca o núcleo urbano de Paranapiacaba. Ainda que muitos deles ainda estejam em estado bruto de desenvolvimento turístico, existe procura e também potencialidade para sua transformação em atrativos culturais. Dentre eles, destacam- se os principais (Ferreira; Passarelli; Santos, 1990; Prosperi; Grostein, 1999; Santo André. Prefeitura Municipal, 2002):

\section{Castelinho}

Localizado num dos pontos privilegiados da Vila, era a casa do engenheiro residente. Assentado sobre uma pequena colina, data de 1897 e um de seus moradores foi Daniel Fox. Com $286,5 \mathrm{~m}^{2}$, a construção abriga um museu com acervo dos moradores da casa e da ferrovia como um todo, dentre os quais relógios antigos, máquina de escrever, artefatos ferroviários etc. O local funciona como Centro de Preservação da História de Paranapiacaba. Funciona das 9 h às 17 h e tem entrada franca.

\section{Museu Funicular}

Administrado pela RFFSA, fica na área de influência da MRS Logística, o pátio ferroviário. Estende-se desde a Ponte Metálica até a $5^{\text {a }}$ Máquina do antigo sistema de funiculares. Conta com um acervo de artefatos ferroviários e expõe o maquinário responsável pelo funcionamento do sistema. Funciona das $9 \mathrm{~h}$ às $17 \mathrm{~h}$ e é cobrada uma taxa de $\mathrm{R} \$ 2,00$.

\section{Igreja Bom Jesus}

Localizada na Parte Alta de Paranapiacaba, a sua construção data de 1889. No início de agosto, há festas religiosas em homenagem ao padroeiro da Vila, Bom Jesus

\section{Entreposto de Artesanato e Culinária}

Localiza-se no antigo SENAI, na Vila Velha. No local são expostos e comercializados, pelos próprios produtores, artigos de artesanato e arte, além de doces e salgados. Funciona das $9 \mathrm{~h}$ às $17 \mathrm{~h}$.

\section{Ateliers}

O projetoAteliers é uma das mais recentes medidas daadministração pública em Paranapiacaba em cooperação com os artesãos da Vila. Em vigor desde o 
primeiro semestre de 2002, o projeto é composto por onze ateliês-residências, no qual os artistas recebem os visitantes e mostram seus trabalhos, que podem ser brinquedos de madeira, bonecos, pinturas e outros.

\section{Casario da Parte Baixa}

A Parte Baixa, pela sua unidade e estilo, formam um complexo de atração. Algumas construções se destacam, apesar de não abertas à visitação permanente, como o Antigo Mercado (1899), o Clube Lira Serrano (1903/ 1907/1938). No geral, as casas geminadas ou isoladas exercem atração pelo tipo de construção inglês, o material usado, o pinho-de-riga.

\section{Complexo da Estação Ferroviária}

Ponto de passagem obrigatório para quem chega de trem à Vila, a Estação de Paranapiacaba foi reconstruída em 1981 após passar por um incêndio. Apesar de estar descaracterizada, ainda conserva a Torre do Relógio, que lembra o Big Ben londrino e voltou a funcionar em 2002. A Passarela Metálica é a única conexão cntre a Parte Baixa e a Parte Alta; de cima dela, pode-se ter uma visão geral de toda a Vila e acompanhar o movimento dos trens de carga que ainda circulam pela ferrovia.

\section{Festival de Inverno}

A subprefeitura estima que cerca de $15 \mathrm{mil}$ pessoas tenham prestigiado o evento em 2002, contra cerca de 13 mil em 2001. Para este ano, foram programadas apresentaçõesculturais de música e a infra-estrutura contou com tendas gastronômicas e restaurantes volantes. Durante o evento, nos fins de semana, a CPTM ampliou os horários dos trens entre Rio Grande da Serra e Paranapiacaba, servindo a Vila com trens a cada hora até às $20 \mathrm{~h}$.

Os questionários aplicados confirmaram os dados que o Plano de Desenvolvimento Sustentável traz sobre as procedências dos visitantes, ou seja, a maioria vem da Região Metropolitana de São Paulo - 57\% da capital e 25\% do grande ABC.

Em relação ao transporte, os resultados mostraram que o fator preço não exerce influência quando do uso do transporte. A começar pelo fato de a maioria dos entrevistados $(42 \%)$ virem de carro próprio, o que indica que não há restrição econômica quando se trata do transporte. O segundo meio de transporte mais usado foi o trem, mas também não há relações com o preço da passagem, pois, dos que usaram apenas o trem ou trem e ônibus, somente $13 \%$ alegaram que o motivo da escolha foi o baixo custo do bilhete, enquanto $57,20 \%$ o fizeram pelo passeio.
Fundamentalmente visitada nos finais de semana, Paranapiacaba recebe basicamente excursionistas ${ }^{6}$ como visitantes, o que se deve à proximidade $c$ facilidade de acesso da capital paulista, principal pólo emissor de visitantes, somado o fato da debilidade dos serviços e ausência de meios de hospedagem. Dos entrevistados, somente $1 \%$ iria pernoitar em Paranapiacaba, em função do incipiente

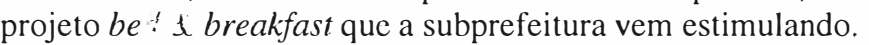

Essa constatação gera um panorama que vem sendo discutido pelos planejadores de turismo para a Vila, pois o excursionista, em sua maioria jovem, pouco utiliza os serviços da Vila, geralmente desrespeita regras de campismo nas áreas de Mata Atlântica e não é conscientizado em relação à preservação ambiental, trazendo, ao invés de benefícios, problemas de ordem pública para a administração local.

Esse quadro é típico de uma área que recebe turistas de forma espontânea, ou seja, na ausência de um plano estratégico de desenvolvimento, os próprios visitantes descobrem os pontos de interesse e cmpreendem a visitação, seguindo critérios que muitas vezes fogem ao conceito de turismo sustentável?.

Porém, com o perfil do visitante entrevistado, pode-se considerar que surge um novo paradigma para o turismo na Vila: famílias e casais com faixa etária maior e motivações ligadas ao patrimônio cultural. A maioria das pessoas entrevistadas (39\%) estão na faixa de idade entre 36 e 50 anos, c $42 \%$ estavam passeando em família. O patrimônio cultural é a principal ou uma das três principais razões para visitar Paranapiacaba para 53\% dos entrevistados, fazendo cair o conceito de o visitante da Vila ter motivações exclusivamente ligadas à natureza.

Os gastos gerais são baixos. A maioria dos entrevistados $(51 \%)$ gastou até $\mathrm{R} \$ 10,00$ no dia e $36 \%$, entre $\mathrm{R} \$ 11,00$ e $\mathrm{R} \$ 30,00$. Considerando-se que $43 \%$ dos visitantes al oçaram ou iriam almoçar na Vila, este gasto médio em consumo de outros produtos da Vila - artesanato, por exemplo - torna-se ainda menor.

No geral, estima-se que o passeio tenha satisfeito os visitantes, uma vez que o índice de intenção de retorno à Vila é de 95\%. Quando perguntados sobre um preço justo para um possível "trem turístico" até Paranapiacaba, pôde-se perceber que a idéia é bem-recebida pelos entrevistados e a média de preço auferida foi de $\mathrm{R} \$ 1$ 1,80.

\section{A Proposta}

Pretende-se neste item relacionar e integrar os temas detalhados anteriormente, segmentando a discussão no turismo cultural e na problemática da ferrovia com

6. A OMT consideraexcursionistas aqueles visitantes que permanecem menos de 24 horas no local, não gerando pernoite

em meios de hospedagem (Barreto, 1999).
" "O desenvolvimento sustentável do turismo ś aquele que vai ao encontro das necessidades dos turistas do presentc e das regiôes receptoras, ao mesmo tempo que protege e garante oportunidades para o futuro. Visa-se, assim, o gerenciamento de todos os recursos, de forma a suprir necessidades econômicas, sociais e estéricas, além de manter a integridade cultural, os processos ecológicos essenciais, a diversidade biológica e o apoio à vicla dos ecossistemas" (WTTC, 2001). 
fins turísticos. O caso de Paranapiacaba serve como uma tentativa de mostrar que a integração entre a ferrovia e o turismo, mormente em sua forma cultural, é tema que tem vários pontos de tangência. Dentre as estratégias de fomento à atividade turística na Vila de Paranapiacaba, assim como possibilidades de ações que podem lograr sucesso a curto-médio prazo, citam-se:

\section{- Educar o visitante para a interpretação}

A questão da educação é de vital importância para o turismo na Vila. Como se pôde perceber pelas visitas, a maior parte do patrimônio histórico ali presente está em péssino estado de conservação. Prova disso são os vagões de trens enferrujando no pátio ferroviário e a falta de interesse em se fazer uma leitura aprimorada dos edifícios históricos do local.

É sério notar que $39 \%$ dos entrevistados consideram que a conservação da Vila está ótima ou boa. Como dito, visivelmente ela está sofrível. Porém, quandoda visita, pouco parece interessar aos visitantes qual é a capacidade de comunicação e a simbologia que o patrimônio da Vila demonstra; interessa-lhes, talvez, só o contato com o "velho", como se o antigo tivesse de ser sucata para se parecer como tal. Esse é um dos mais notáveis sintomas da falta de especialização das visitas. Ou seja, do tom descompromissado que ela apresenta.

Relacionando essa problemática com o conceito de preservação ativa, percebe-se o porquê da passividade do visitante. Uma vez que somente dois prédios - o conjunto do Museu Funicular e o Castelinho - têm uma função turística e, teoricamente, prestam-se efetivamente a uma atividade de lazer, o visitante pouco tem a interpretar. Ou seja, poucos subsídios e estímulos são dados para que se desencadeie uma atividade turística voltada à educação.

Uma atividade importante que se pode destacar é o projeto Ateliers. Com sinalização específica para cada estabelecimento e um folheto de divulgação, notase que os visitantes do núcleo urbano já vêm procurando esse tipo de atrativo. Neste contex to e considerando os pressupostos da interpretação, nota-se que ao se deparar com o artesanato ou qualquer outro tipo de produto criado pelos artistas, o visitante ganha também em informações, pois conhece não só a criação, mas o criador e o ambiente no qual ele foi forjado.

A suigrestão é tentar ao máximo atrair a atenção do visitante também em outros setores do patrimônio cultural, como no próprio urbanismo da Parte Baixa, dos acervos do Museu Funicular e do Castelinho, que estão descontextualizados nestes locais e não contam com uma integração a contento.

De forma geral, se o visitante dispõe-se a visitar a Vila, isso denota que mesmo que ele não saiba exatamente as razões, há uma curiosidade latente a ser explorada. A maioria dos visitantes entrevistados (58\%) durante a pesquisa de campo, estava em Paranapiacaba pela primeira vez, o que significa que, de alguma forma, a informação sobre o local está sendo disseminada e houve interesse em conhecê-lo ao vivo. Desses entrevistados em primeira visita, somente $6 \%$ disseram que não pretendiam voltar, denotando que não existe um sentimento de decepção generalizacio com o passeio.

- A ferrovia, como produto turístico, compondo o destino

Em face do fato da morosidade de uma possível retomada dos transportes de passageiros a longo prazo, não é verossímil ufanar a volta do ferroviarismo no país de forma instantânea, uma vez que o modelo rodoviarista, ademais de sua expressão econômica e prática, já é um conceito culturalmente arraigado. No entanto, pensar a ferrovia de forma a utilizá-la em pequenos trechos turísticos, com destaque para as paisagens ou somente pelo passeio, é algo bastante factível à realidade de algumas regiões, como a de Paranapiacaba. Este fato fica claro quando se nota que mais de $57 \%$ dos visitantes utilizam o trem em função do passeio e a minoria pelo baixo custo $(5,7 \%)$ ou praticidade $(11,4 \%)$

Inserindo a temática da ferrovia nas discussões do turismo em Paranapiacaba, percebe-se que uma ligação ferroviária entre São Paulo, o maior centro emissor de visitantes, e a Vila seria algo que enriqueceria muito seus atrativos. Apesar dos empecilhos à criação de uma linha com fins turísticos, vê-se que o ambiente é extremamente propício à discussão do assunto.

A CPTM tem suas limitações, o que se explica com base no estatuto dessa estatal. Uma vez que não é seu objeto social realizar o transporte turístico, a atual operação iُu linhas de trens a Paranapiacaba é algo que, legalmente, não deveria prosseguir nem estimulado. As limitações são, além de legais, técnicas, pois toda vez que a CPTM faz uso da via férrea fora de sua jurisdição - como é o caso entre Rio Grande da Serra e Paranapiacaba -, gera-se um custo extra ao sistema não compensado pelo número de embarques pagos à Vila.

Já que este tipo de transporte, em uma situação ideal, não deveria ser feito pela CPTM, nada impede que outras entidades - públicas ou privadas - pleiteiem a atuação neste trecho. Como uma entidade que tem se destacado em âmbito nacional, a Associação Brasileira de Preservação Ferroviária (ABPF) seria uma alternativa de peso para que se criasse uma linha turística à Vila de Paranapiacaba.

Dentro da temática que se vem discutindo para o turismo na Vila, a política de preservação da ABPF é uma possibilidade viável para a revitalização da ferrovia na Vila.

Através da aplicação dos questionários na Vila, a idéia do turismo vinculado à ferrovia é quase que unanimemente aceita pelos visitantes de hoje. O preço médio por eles sugerido - R \$11,80 - para um passeio entre São Paulo e Paranapiacaba é algo que está nos conformes com outras ferrovias turísticas existentes. O preço do passeio de Campinas de ida e volta é de $\mathrm{R} \$ 15,00$ e o do Corcovado, $\mathrm{R} \$ 20,00$. Isso mostra que, num cenário de ferrovias turísticas, a aceitação do visitante de hoje de Paranapiacaba está dentro da realidade do setor, ou seja, está em conformidade com os preços : 'icados em outras ferrovias turísticas.

É claro que, no caso da aplicação de uma linha turística em Paranapiacaba há de se analisarem todas as questões legais e de viabilidade econômica. No entanto, em conversas informais com funcionários da RFFSA e da CPTM, as duas principais 
entidades relacionadas ao assunto da ferrovia na região, viu-se que não se criarão empecilhos para uma negociação ou articulação de uma cenário diferente para o turismo na Vila.

Portanto, deixam-se como sugestões, duas alternativas:

a) Trem turístico no percurso Estação da Luz a Paranapiacaba: seria um trem com poucas paradas; talvez somente em São Caetano, Santo André e Mauá, pois o mercado emissor está também nessas regiões;

b) Trem turístico de Rio Grande da Serra a Paranapiacaba: na impossibilidade da instal Justifica-se ainda pelo apelo paisagístico do trecho, pois, sendo a região do Grande ABC densamente povoada e de forma caótica, um trem que percorresse essa área pouco ou nada teria de interessante do ponto de vista da paisagem. Assim, adotando-se a segunda hipótese, há um ganho no custo-benefício para o passeio, uma vez que de Rio Grande da Serra em diante a paisagem é majoritariamente a densa Mata Atlântica.

Em ambos os casos, imagina-se uma "MariaFumaça" para opasseio, uma vez que se intenta com este trabalho valorizar e mitigar temas ligados à história local e regional. Dessa forma, uma composição ferroviária antiga seria capaz de ambientar, desde antes da chegada, o turista num contexto no qual se explorarão aspectos culturais e históricos de Paranapicaba - dando maior enfoque, então, para o turismo cultural. Além disso, serviços de monitoria e de bordo são recomendáveis como forma de gerar um ambiente confortável e rico em informações para o visitante.

Segundo dados da ABPF, a entidade vem conseguindo bons resultados com restauração de locomotivas e carros de passageiros atualmente avariados; atualmente são 11 locomotivas restauradas (Associação Brasileira de Preservação Ferroviária, 2002). Isso também é um ponto forte para a defesa desta tese, pois, uma vez que o material rodante não é escasso, pensar-se numa realocação de locomotivas para o trecho de Paranapiacaba já não é uma atitude descabida.

Cc : ¿ : maior desafio que surge para o sucesso da proposta surge a articulação de forças institucionais, ou seja, as partes envolvidas devem discutir a possibilidade de sua real viabilidade. Sendo o objetivo maior da ABPF a preservação da cultura e patrimônio ferroviários, ao menos um caminho parece surgir livre para a concretização de uma ferrovia turística em Paranapicaba. Assim, consideradas todas as potencialidades da Vila e a conjuntura próxima, a sugestão é o poder público de Paranapiacaba aproximar as discussões com a ABPF, a fim de que se desenvolvam progressos em favor do turismo ferroviário.

\section{- O morador deve participar}

Ainda que não tenha sido feita uma pesquisa por questionário, como feito com os visitantes, pôde-se perceber em conversas informais algumas questões problemáticas em relação à participação dos moradores no processo de planejamento turístico.
Goodey (2002), argumenta em favor da interpretação do patrimônio:

(...) envolvendo-se desde o inicio a população do lugar, a interpretação pode ser um poderoso aliado do desenvolvimento local sustentável. Uma comunidade que não conhece a si mesma dificilmente poderá comunicar a importância de seu patrimônio, seja na interação comos visitantes, seja na sensibilização das operadoras. A prática interpretativa deve, portanto, promover a discussão entre os vários segmentos sociais sobre aquilo que torna seu lugar especial e diferente. Deve também levar moradores a (re)descobrir novas formas de olhar e apreciar seu lugar, de forma a desenvolver entre eles atitudes preservacionistas. Finalmente, deve despertarnovas vocaçōes e possibilitar oportunidades de trabalho e renda ligados ao turismo.

Neste sentido, surge um novo paradigma para o pensar e fazer turístico em Paranapiacaba: criar um sistema de interpretação com moradores com pouca identidade com o local. Assim, o vínculo com a história da Vila e a afeição com o local fica dificultado. Independentemente das medidas empreendidas, deve-se ter como eixo principal do processo que ações intrusivas e pouco democráticas estão totalmente em desacordo com as práticas de turismo sustentável. O estudo c conhecimento de outras áreas que passaram por uma revitalização c rcssignificação é de extrema importância para que não se cometam abusos para com a comunidade local. Isso se explica pelo fato de que, além das questões morais e legais, a prática de interpretação do patrimônio considera o autóctone um personagem-chave para o sucesso das ações.

Propõe-se, como exemplo, que se faça uma revisão de como foram as mudanças ocorridas no Pelourinho, em Salvador, que, apesar de hoje reconhecido como uma área importante para o turismo, era habitado por uma população de baixa renda e que pouco colaborava para a preservação do patrimônio ali existente.

Mesmo sendo uma fase indispensável no processo de planejamento turístico, a participação da comunidade, em princípio, não é confortável e fácil. Deve ser feito em forma de conselhos representativos, que congreguem pessoas de todos os setores e interesses envolvidos com as mudanças esperadas. A dificuldade inicial reside, porém, da tradicional distância entre essas classes, que costumam não manter relações sociais cotidianas (Goodey, 2002).

- Incentivo ao excursionismo e critérios para implantação de meios de hospedagem

O Plano Patrimônio (2002) traz estratégias de desenvolvimento até o ano 2010, divididos entre 2002 a 2005 e 2005 a 2010. Para o ano de 2005, esperam-se 500 mil visitantes, dos quais 410 mil serão excursionistas e 90 mil turistas. Em 2010 o número de visitantes é estimado cm 800 mil.

A primeira obscrvação que deve ser feita é que 800 mil pessoas por anoé um 
número extremamente exagerado para ser assimilado por uma população autóctone tão pequena-cerca de 2 mil pessoas em 2002. Isso significa cerca de 2.200 visitantes por dia se considerado um fluxo de visitação constante durante os sete dias da semana - o que, na prática, é impossível.

Exemplo claro do caos que se instala em situação semelhante é o litoral paulista. Cidades como Guarujá que têm população flutuante de turistas maiores que a do próprio município, passam por situações caóticas, com o colapso do sistema de água, esgoto, abastecimento de gêneros alimentares, trânsito, etc. Por isso, sugerese que essas metas sejam revistas e, no mesmo sentido, utilizarem-se critérios rigorosos para instalação de meios de hospedagem, pois, além do cuidado com o número de pessoas afluindo para Paranapiacaba, há de se atentar à sazonalidade.

Considerando que o maior público da Vila é da Grande São Paulo, o acesso é bastante facilitado, principalmente pela pequena distância. Assim, o apelo para que pessoas que estão muito perto de casa em passeio fiquem mais de um dia em uma mesmalocalidade éalgodelicado. Por isso, propõem-se as atividades de excursionismo controlado, enquanto a questão da hospedagem em Paranapiacaba não se cria e consolida. Como argumentado anteriormente, a sazonalidade semanal em Paranapiacaba é algo bastante nítido e, para se reverter esse quadro, demandam-se tempo e políticas consistentes e contínuas de planejamento turístico, que devem contemplar um profundo estudo de capacidade.

Por isso, a sugestão é tentar criar um cenário de excursionismo em que o visitante aumente seu gasto médio e os problemas tradicionais desta prática (degradação do patrimônio, excesso de lixo, etc.) sejam amenizados com práticas interpretativas do patrimônio e visitas educativas. Para que o visitante gaste mais, uma primeira atitude seria criar uma marca registrada de Paranapiacaba e induzir os artesãos a contemplá-la na sua reprodução em suvenires, na medida do possível para cada tipo de especialidade artística. Suvenires, além de aumentar o gasto do visitante, são uma boa forma de desencorajar o vandalismo e a degradação do patrimônio.

\section{Conclusōes}

Considerada "problema" conceitual para os estrategistas da administração pública e a população acadêmica de áreas correlatas, Paranapicaba, como tema de discussão científica, mostrou-se perfeitamente tratável metodológica e conceitualmente sob os auspícios da Academia, especialmente para o turismo.

Na prática, vendo que a figura composta "trem-turismo" é uma das perspectivas dos administradores da Vilae, ao mesmo tempo, o eixo temático principal desta pesquisa, entende-se a proximidade entre o teórico-acadêmico e o prático-cotidiano. Para tanto, sugeriu-se, com base em observação prática, o trabalho de êxito que a ABPF vem realizando em outras áreas, no sentido de valorizar o patrimônio histórico relacionado à cultura ferroviária.

No campo do turismo cultural - nitidamente em reconhecimento pela Unesco
$(2001)^{8}$-, a temática ferroviária é um elemento-chave para que se potencializem as formas de atração à Vila, criando-se um consórcio entre os atrativos históricoculturais e a ferrovia. Para aplicar o turismo, segundo os quesitos da sustentabilidade propôs-se, atrelado ao conceito de preservação ativa, o método da interpretação do patrimônio, ainda incipiente no Brasil.

Vislumbram-se, portanto, dois novos paradigmas para o turismo em Paranapiacaba. O primeiro é aceitar o excursionismo como uma atividade possível e sustentável. Geralmente, associa-se esta prática às visitas degradantes para o destino e pouco educativas para o visitante. No entanto, se feito com bastante controle e de forma interpretativa, ela pode ser um substrato para o turismo de sucesso. O segundo paradigma foi criar uma conjuntura, ainda que primeiramente no nível teórico, que propicie discussões promissoras no campo do turismo ferroviário. Como é comum, as propostas para Paranapiacaba são geralmente recebidas com desconfiança decortrente da grande gama de projetos e trabalhos já realizados e quase todos não aplicados. Por isso, com o contexto que se criou e as possibilidades exploradas in loco e em sucessivos encontros e entrevistas, mostra-se que já existe uma ante-sala para que se adentre a questão do turismo ferroviário como uma atividade verossímil à Vila de Paranapiacaba.

Além de tentar trazer uma contribuição real para o planejamento turístico do local - amplo e sistêmico -, intentou-se demonstrar e comprovar que o turismo, quando feito de forma saudável e sustentável, é uma ferramenta poderosíssima de reordenação do espaço e criador de alternativas de desenvolvimento urbano e social integrados.

\section{Referências}

ANDRADE, José Vicente de. 2000. Turismo - fundcumentos e e dimensiñes. São Paulo: Ática. ASSOCIAÇÃO BRASILEIRA DE PRESERVACC̄O FERROVIÁRIA. Disponivel em <www.abpf hpg com br> Acesso em ago. de 2002

BARBOSA, Fátb:o dos Santos. 2001. Chegou a hora do turismo sobre trilhos. O Estudo de S. Paulo, 18 set. 2001. p. V2.

P. V2.
BARRETO. 1999. Munual de inicicuçūoo ao turismo. Campinas: Papirus.

CALDEIRA, Jorge. 1997. Mauci - Empresśririo do Império. São Paulo: Cia. das Letras.

CRUZ, Rita de Cássia. 2000. Políitica de turismo e território. São Paulo: Contexto.

CYRINO, Fábio R. P. 2000. Cufé, férro e argila - A história da implantaçüo e consolidaçūo da Empresa The San Paulo

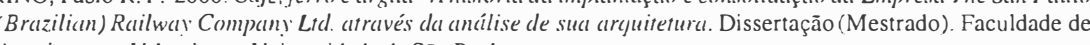
Arquiteturae Urbanismo, Universidade de Sāo Paulo.

ESTA FALTANDO TURISMO FERROVIARIO NO BRASIL. Revista Ferrovia, São Paulo, maio/jun. 1985.

FANI, Ana, A. C. 2001. A cidcude - O homem e a cidude; a cidade e o cidadīo; de quem éo solo urbano?" São Paulo:

Contexto.
FERREIRA, João; PASSARELLI, Sílvia H.: SANTOS, Marco Antonio P. 1990; Parunapiacubal - Estudos e memóricls.

8. A United Nations Educational, Scientific and Cultural Organization (Unesco) afirma que encorajará, entre os países membros, a promoção do turismo cultural genuíno. Esta declaração garante que o turismo cultural responsáve
desenvolvido na Vila de Paranapiacaba estará de acordo com a política da organização. 
Santo André: Prefeitura Municipal de Santo André / GIPEM

estudos das estaç̧̃ès ferrovicírias paulistas. Dissertaçāo (Mestrado Fa do baulo GOODEY, Bria

patrimônio - um exercício do olhar. Belo Horizonte: UFMG/ Território Brasilis. ria da educuçção. São Paulo: Summus. MINISTÉRIO DOS TRANSPORTES. 2002. Disponível em <www.transportes.gov.br>, Acesso em: ago. 2002.

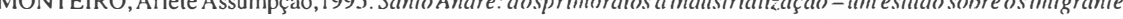
uo longo da São Paulo Railwạ!. Dissertação (Mestrado). Faculdade de Filosofia, Letras, Ciências Humanas. Universidade de Săo Paulo.

MURTA, Stela Maris; ALBANO, Celina. (Org.). 2002. Interpretar o patrimônio - um exercicio do ollhar. Belo Horizonte: UFMG / Território Brasilis

AGE, Sthepen J. 2001. Trimporte e Turismo. Porto Alegre: Bookman.

AALHARES, Guilherme Lohan. 2002. Transportes turísticos. São Paulo: Aleph.

PER

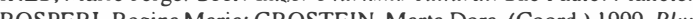

RECIFE. PREFEITURA MUNICIPAL. s.d. Bairro do Recife. I folder. (Mestrado). Faculdade de Filosofia, Letras, Ciências Humanas, Universidadede São Paulo.

SANTO ANDRE. Prefeitura Municipal. 2002. Pluno Putrimônio. Santo André. I CD-ROM.

SANTOS, Chiro ?.002. Ferrovias continuam penduradas no BNDES. Follua de S. Paulo, 28 abr. 2002.

UNESCO. 20,... iviedtum-term Struteg!: Paris

WTTC. 2002. Disponivel em: <www.wttc.org> Acesso em: ago. 2002.

\section{Recebido em 28/10/02}

Aprovado em 10/12/02

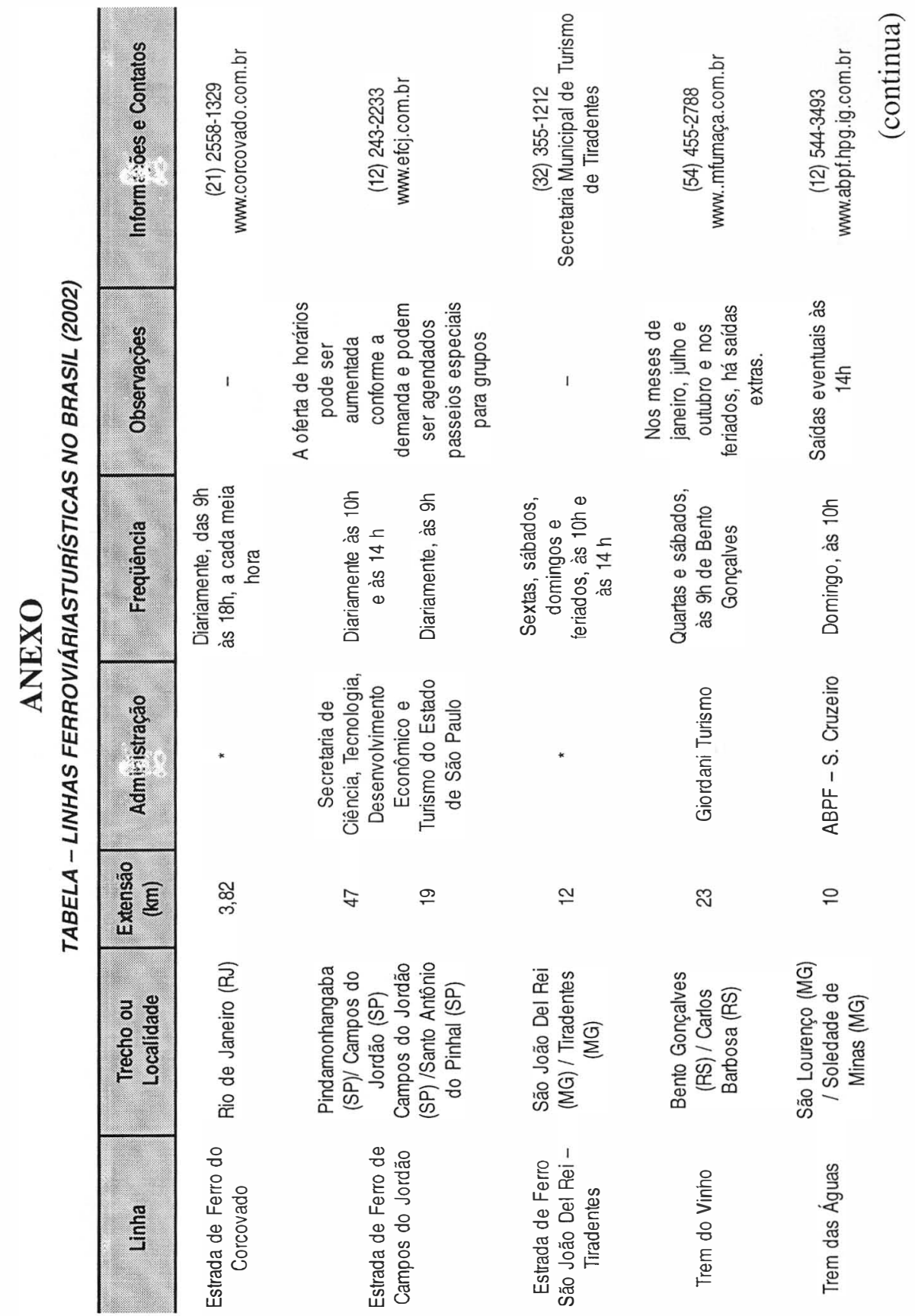




\begin{tabular}{|c|c|c|c|c|c|c|}
\hline Linha: & $\begin{array}{l}\text { Trecho ou } \\
\text { Localidade }\end{array}$ & $\begin{array}{c}\text { Extensão } \\
(\mathrm{km})\end{array}$ & Administração & Frequência: & Observaçóes & Informaçöes e Contatos \\
\hline $\begin{array}{l}\text { Estrada de Ferro } \\
\text { Curitiba - Paranaguá }\end{array}$ & $\begin{array}{l}\text { Curitiba (PR) - } \\
\text { Paranaguá (PR) }\end{array}$ & 110 & $\begin{array}{l}\text { Serra Verde } \\
\text { Express }\end{array}$ & $\begin{array}{l}\text { De quinta a } \\
\text { domingo, às } 8 \mathrm{~h}\end{array}$ & $\begin{array}{l}\text { Nos oeriodos de } \\
\text { alta estação (de } \\
\text { dezembro a } \\
\text { fevereiro e em } \\
\text { julho), as saídas } \\
\text { são diárias. Os } \\
\text { trens fazem parada } \\
\text { em Morretes. }\end{array}$ & $\begin{array}{c}\text { (41) } 323-4007 \\
\text { unw.serraverdeexpress.com.br }\end{array}$ \\
\hline $\begin{array}{l}\text { Viação Férrea } \\
\text { Campinas - } \\
\text { Jaguariúna }\end{array}$ & $\begin{array}{l}\text { Distrito de Anhumas } \\
\text { (SP) / Jaguariúna } \\
\text { SP) }\end{array}$ & 24 & ABPF - Campinas & $\begin{array}{c}\text { Sábados e } \\
\text { domingos às } 10 h 10 \\
\text { e aos domingos às } \\
16 \text { h10 (percurso } \\
\text { inteiro) }\end{array}$ & $\begin{array}{l}\text { Durante a semana, } \\
\text { funciona para } \\
\text { atendimento de } \\
\text { grupos escolares }\end{array}$ & $\begin{array}{c}\text { (19) 3207-3637 } \\
\text { www.abpf.hpg.ig.com.br }\end{array}$ \\
\hline $\begin{array}{l}\text { Maria Fumaça de } \\
\text { Rio Negrinho }\end{array}$ & $\begin{array}{l}\text { Rio Negrinho (SC) / } \\
\text { Rio Natal (SC) }\end{array}$ & 80 & $\begin{array}{l}\text { ABPF - Rio } \\
\text { Negrinho }\end{array}$ & $\begin{array}{l}\text { Todo segundo } \\
\text { sábado do mês, às } \\
10 \mathrm{~h}\end{array}$ & - & $\begin{array}{c}\text { (47) 644-7777 } \\
\text { uww.abptsc.com.br }\end{array}$ \\
\hline Trem da Mantiqueira & $\begin{array}{l}\text { Cruzeiro (SP) / Alto } \\
\text { da Serra - Cruzeiro } \\
\text { (SP) }\end{array}$ & 23 & ABPF - Cruzeiro & $\begin{array}{c}\text { Aos domingos, às } \\
10 \mathrm{~h}\end{array}$ & $\begin{array}{l}\text { Temporariamente } \\
\text { com serviços } \\
\text { interrompidos }\end{array}$ & $\begin{array}{l}\text { (12) 544-3493 } \\
\text { uww. abpt.hpg.ig.com.br }\end{array}$ \\
\hline $\begin{array}{l}\text { Estrada de Ferro do } \\
\text { Memorial do } \\
\text { Imigrante }\end{array}$ & São Paulo (SP) & 1 & ABPF - São Paulo & $\begin{array}{c}\text { Domingos e } \\
\text { feriados, das 10h às } \\
17 \mathrm{~h}\end{array}$ & $\begin{array}{l}\text { O passeio de trem } \\
\text { é feito no Memorial } \\
\text { do Imigrante. Há } \\
\text { ainda um passeio } \\
\text { de bonde nas } \\
\text { redondezas do } \\
\text { Memorial com } 600 \mathrm{~m} \\
\text { de percurso. }\end{array}$ & $\begin{array}{l}\text { (11) 6693-0917 } \\
\text { uww.memorialdo } \\
\text { imigrante.sp.gov.br }\end{array}$ \\
\hline
\end{tabular}

TABELA (continuação)

\begin{tabular}{|c|c|c|c|c|c|c|}
\hline Linha & $\begin{array}{l}\text { Trecho ou } \\
\text { Localidade }\end{array}$ & $\begin{array}{l}\text { Extensäo } \\
(\mathrm{km})\end{array}$ & Administração & Frequéncia & Observacóes & Informagóes e contatos \\
\hline Trem de Itatinga & Bertioga (SP) & 7 & $\begin{array}{l}\text { Cia. Doc: ¿ do } \\
\text { Estado de São } \\
\text { Paulo }\end{array}$ & $\begin{array}{l}\text { Visita } \infty \mathrm{m} \\
\text { autorizaçāo da } \\
\text { CODESP }\end{array}$ & $\begin{array}{l}\text { A Suiña Turismo } \\
\text { tem autorização } \\
\text { para realizar } \\
\text { passeios a ltatinga } \\
\text { em três do mingos } \\
\text { do mês. }\end{array}$ & $\begin{array}{l}\text { Suiña Turismo } \\
\text { (13) } 33173667\end{array}$ \\
\hline Trem do Fórro & $\begin{array}{l}\text { Recife (PE) ao } \\
\text { Cabo de Santo } \\
\text { Agostimo (PE) }\end{array}$ & 42 & Se rambi Turismo & $\begin{array}{l}\text { Variável, geralmente } \\
\text { aos fins de semana }\end{array}$ & $\begin{array}{c}\text { Por falta de } \\
\text { se gurança das vias, } \\
\text { desde } 2002 \text { a } \\
\text { CBTU nāo pe mite } \\
\text { mais o passeio ra } \\
\text { rota Recife (PE) a } \\
\text { Caruaru (PE). }\end{array}$ & $\begin{array}{c}\text { (81) } 3423.5000 \\
\text { www.tremdofo iro.com.br }\end{array}$ \\
\hline
\end{tabular}

Fontes: PALHARES (2002); Guia Brasil - Quatro Rodas (2002); contatos telefônicos com as administradoras e visitas a

"sites" oficiais.

* Dados a serem confirmados. 